Invited critical review

\title{
Toll-like receptors and macrophage activation in atherosclerosis
}

\author{
Anusha N. Seneviratne, Bawani Sivagurunathan, Claudia Monaco *
}

Kennedy Institute of Rheumatology, Faculty of Medicine, Imperial College, London, United Kingdom

\section{A R T I C L E I N F O}

\section{Article history:}

Received 24 May 2011

Received in revised form 29 July 2011

Accepted 12 August 2011

Available online 22 August 2011

\section{Keywords:}

Atherosclerosis

Innate immunity

Monocytes

Macrophages

Cell signalling

\begin{abstract}
A B S T R A C T
Atherosclerosis is a multi-factorial inflammatory disease and is the primary initiator of coronary artery and cerebrovascular disease. Initially believed to be exclusively lipid-driven, recent evidence demonstrates that inflammation is a significant driving force of the disease. Cellular components of innate immunity, for example monocytes and macrophages, play a predominant role in atherosclerosis. Toll-like receptors (TLRs) are the most characterised innate immune receptors and recent evidence demonstrates an important role in atherogenesis. Engagement of TLRs results in the transcription of pro-inflammatory cytokines, foam cell formation and activation of adaptive immunity. Recently they have also been implicated in protection from vascular disease. In this review, we detail the role of the innate immune system, specifically macrophages and TLR signalling, in atherosclerosis and acute cardiovascular complications, and thereby identify the potential of TLRs to act as therapeutic targets.
\end{abstract}

(C) 2011 Elsevier B.V. All rights reserved.

\section{Contents}

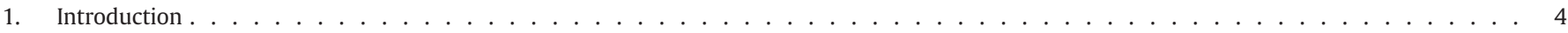

2. Atherosclerosis is an inflammatory disease . . . . . . . . . . . . . . . . . . . . . . . . . . . . . . 4

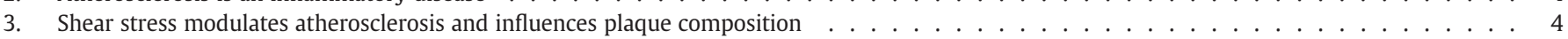

4. Innate immunity is crucial in atherosclerosis . . . . . . . . . . . . . . . . . . . . . . . . . . . . . . . . 5

4.1. Pattern recognition receptors (PRRs) . . . . . . . . . . . . . . . . . . . . . . . . . . . . . . . . . . . . . . . . . . 5

4.1.1. Toll-like Receptors (TLRs) . . . . . . . . . . . . . . . . . . . . . . . . . . . . . . . . . . . . . . . . . . . 5

4.1.2. TLR signalling pathways . . . . . . . . . . . . . . . . . . . . . . . . . . . . . . . 5

4.1.3. Toll-like receptor ligands . . . . . . . . . . . . . . . . . . . . . . . . . . . . . . . . . . . . . . . . . . . . 5

4.1.4. Expression of TLRs in atherosclerosis . . . . . . . . . . . . . . . . . . . . . . . . . . . . . . . 6

4.1.5. Role of TLRs in atherosclerosis . . . . . . . . . . . . . . . . . . . . . . . . . . . . . . . . . . . 8

4.2. Activation of innate immune cells by TLRs in atherosclerosis . . . . . . . . . . . . . . . . . . . . . . . . . . . . . . . 8

4.2.1. Mast cells . . . . . . . . . . . . . . . . . . . . . . . . . . . . . . . . . . . 8

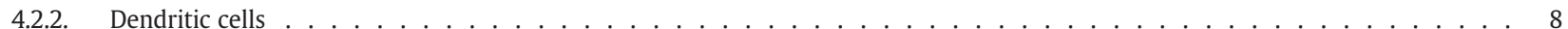

4.2.3. Monocytes . . . . . . . . . . . . . . . . . . . . . . . . . . . . . . . . . . . . 9

4.2.4. Macrophages . . . . . . . . . . . . . . . . . . . . . . . . . . . . . . . . . . 9

4.2.5. Are TLRs critical for macrophage polarisation and activation in atherosclerosis? . . . . . . . . . . . . . . . . . . . . . 11

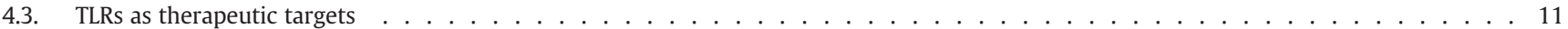

5. Conclusions . . . . . . . . . . . . . . . . . . . . . . . . . . . . . . . . . . . . . . . . . . . 11

Acknowledgements . . . . . . . . . . . . . . . . . . . . . . . . . . . . . . . . . . . 12

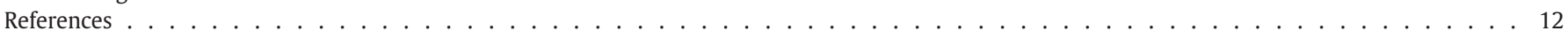

Abbreviations: TLR, Toll-like receptor; PAMP, Pathogen associated molecular pattern; LDL, Low density lipoprotein; SMC, Smooth muscle cell; VCAM-1, Vascular cell adhesion

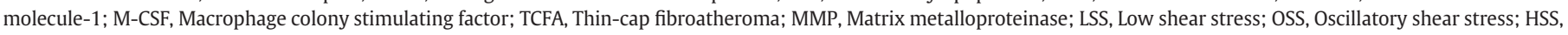

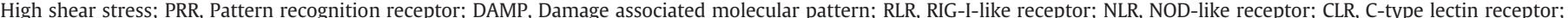

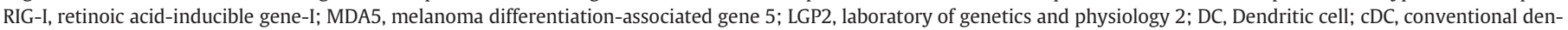
dritic cell; mDC, myeloid dendritic cell; IDC, lymphoid dendritic cell; GM-CSF, granulocyte-macrophage colony-stimulating factor.

* Corresponding author at: Kennedy Institute of Rheumatology, University of Oxford, 65 Aspenlea Road, London W6 8LH, United Kingdom. Tel.: + 44 208 383 5337; fax: + 44208 3834499.

E-mail address: claudia.monaco@kennedy.ox.ac.uk (C. Monaco). 


\section{Introduction}

Atherosclerosis is the primary initiator of coronary artery and cerebrovascular disease; being responsible for $29 \%$ of deaths worldwide [1]. Initially believed to be solely driven by risk factors such as family history, diabetes, hypercholesterolaemia, smoking and hypertension [2], recent evidence has defined inflammation as a fundamental component of its pathogenesis [3].

The innate immune system acts as the first barrier against invading pathogens. Pathogen-associated molecular patterns (PAMPs) activate various families of pattern-recognition receptors (PRRs); the most extensively characterised family being Toll-like receptors (TLRs) [4]. Signalling downstream of TLRs may drive immune responses such as leukocyte recruitment and pro-inflammatory cytokine production exacerbating disease. In inflammatory diseases like atherosclerosis, a bias towards pro-inflammatory stimuli chronically activates innate immunity and dampens anti-inflammatory mechanisms.

In this review, we examine the role of TLRs in the activation of key immune cells such as monocytes and macrophages, atherosclerotic plaque development and its complications, and the potential of these signalling proteins to act as therapeutic targets against atherosclerosis.

\section{Atherosclerosis is an inflammatory disease}

Atherosclerosis involves interactions between blood-borne mononuclear immune cells exogenous of the vessel wall, and the endogenous cell types such as the endothelium and smooth muscle cells (SMCs). Some pathologists consider intima cushions, characterised by SMC proliferation and proteoglycan deposition, as the precursors of human atherosclerotic lesions. Fatty streaks, which can subsequently develop, are considered to be early atherosclerotic lesions. In conditions of hyperlipidaemia, low density lipoproteins (LDLs) enter the intima, the innermost layer of the vessel wall at sites of permeability, where they may undergo a variety of modifications including oxidation [5]. Pro-inflammatory cytokines and mmLDL upregulate endothelial cell expression of selectins and VCAM-1, facilitating monocyte entry into the intima [6]. OxLDL stimulates endothelial cells and SMCs to secrete monocytic maturation factors such as M-CSF. Monocytes differentiate into macrophages, phagocytose modified lipoproteins - predominantly via the scavenger receptors AI and CD36 [7] - and become foam cells [8]. Fatty streaks (or intimal xanthomas) are primarily composed of foam cells and a few SMCs.

When macrophage foam cells infiltrate the lipid pool and apoptose increasing the free cholesterol content, a lipid necrotic core develops [9]. Macrophages secrete growth factors stimulating an influx of SMCs, collagen synthesis and extracellular matrix deposition, forming a fibrous cap beneath the endothelium [3]. The formation of a fibrous cap maintains plaque integrity and avoids contact of the thrombogenic necrotic core with flowing blood [10] creating a mature fibroatheroma. Microvessels can form around the lipid core as neovascularisation from the adventitia occurs; leakage of these vessels leads to intraplaque haemorrhage [11] (Fig. 1).

Mature fibroatheromas are classified as "stable" or "vulnerable" the latter are also referred to as thin-cap fibroatheromas (TCFAs) [12]. Stable lesions tend to be smaller with low macrophage and lipid content, high SMC and collagen content, reduced matrix metalloproteinase (MMP) activity and a thick fibrous cap compared to TCFAs [13]. Apoptosis or clearance of SMCs $[13,14]$ and matrix degradation by MMPs [15] may cause thinning of the cap creating a TCFA [12], which is rupture-prone and is considered the highest risk phenotype for major cardiovascular events [15]. TCFAs are characterised by a large necrotic core and numerous macrophages [16]. Fibrous cap rupture exposes the pro-thrombogenic tissue factor-rich necrotic core and material present following intraplaque haemorrhage [6]. The coagulation cascade then forms a deep thrombus which can protrude into the lumen [17]. Endothelial erosion [11] and intraplaque calcified nodules also trigger thrombosis [18]. Plaque rupture is often asymptomatic and its healing leads to discontinuous plaque progression. However if plaque rupture leads to sudden occlusion of blood flow, acute myocardial damage follows.

\section{Shear stress modulates atherosclerosis and influences plaque composition}

Atherosclerosis displays an uneven distribution throughout the vascular tree suggesting a relationship with local blood flow dynamics [19]. An inverse relationship between wall shear stress and artery wall thickness has been demonstrated in the coronary arteries [20]. Laminar blood flow in a straight vessel imposes high shear stress (HSS) on the endothelium. Curvatures, branches and stenoses in the arterial tree

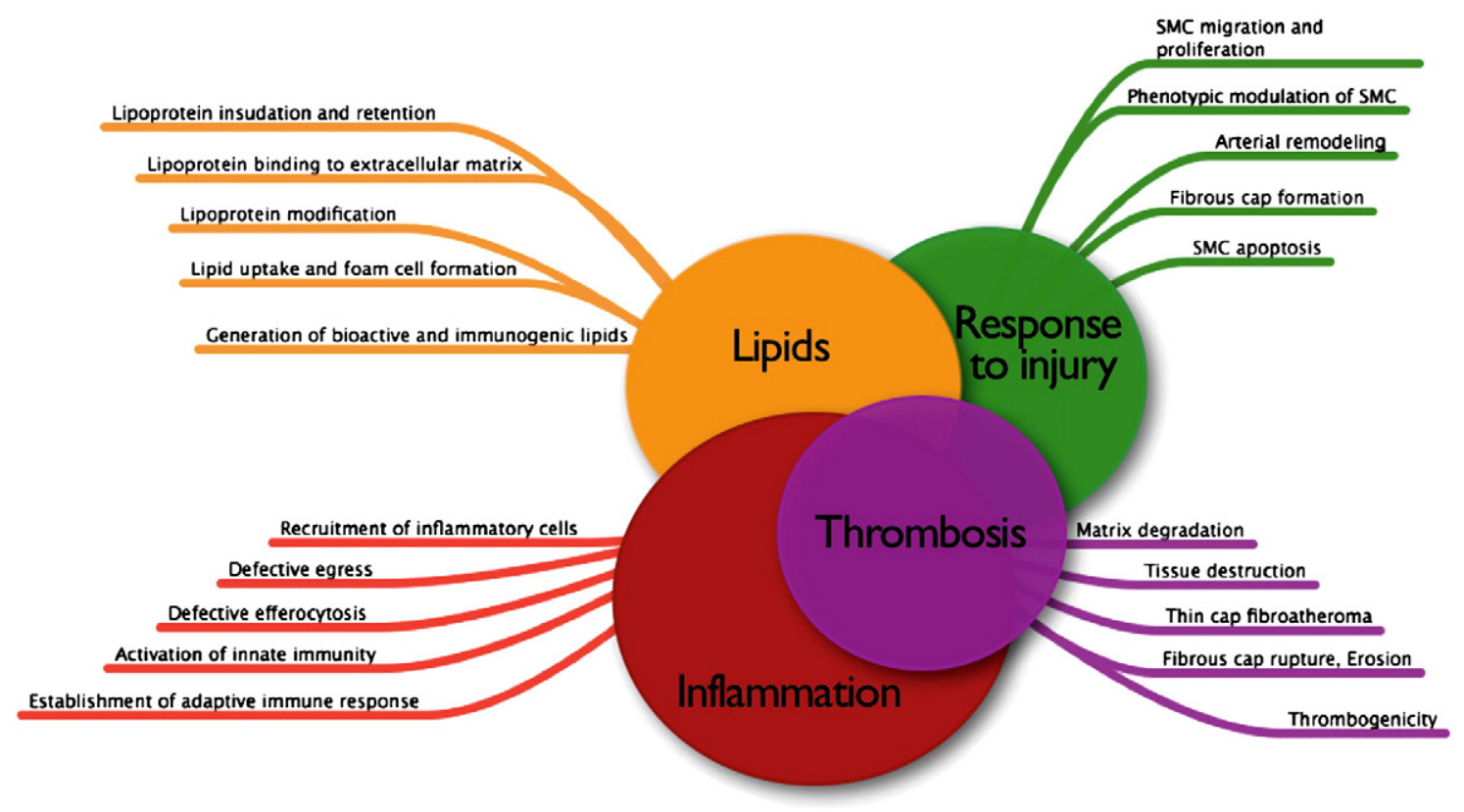

Fig. 1. The multiple features involved with inflammation in atherosclerotic plaque development. 
alter blood flow dynamics. In curved vessels, the vessel wall on the inner curvature experiences low shear stress (LSS). Oscillating blood flow occurs at non-planar branch points or downstream of stenoses creating oscillatory shear stress (OSS). These complex blood flow patterns are considered pro-atherogenic [19].

Different patterns of shear stress can affect plaque morphology. OSS promotes stable plaque formation while LSS associates with the development of vulnerable plaques [13]. However LSS and a vulnerable plaque phenotype are insufficient for plaque rupture. Positive remodelling can maintain normal shear stress values [21]. However protrusion of the plaque increases local shear stress patterns [20]. The surface of the lesion's proximal segment is subjected to HSS and high strain while the surface of the distal segment experiences OSS [22]. In humans, the proximal segment has a higher frequency of fibrous cap rupture sites and intraplaque apoptotic material [23], while the distal segment is more abundant in SMCs and collagen $[16,24]$. It is believed that LSS and OSS promote initial atheroma development, but HSS is thought to encourage plaque rupture in stenosed arteries [23]. Yet the downstream segment is susceptible to thrombosis via endothelial erosion as this region in human carotid plaques displays a higher rate of endothelial cell apoptosis [25].

\section{Innate immunity is crucial in atherosclerosis}

The innate immune system is the body's first line of defence against invading pathogens. Innate immune cells recognise highly conserved pathogen-associated microbial patterns (PAMPs) via pattern recognition receptors (PRRs), which are germline encoded receptors [26]. Recent evidence has shown that PRRs also recognise endogenous molecules termed damage associated molecular patterns (DAMPS) from damaged cells [26]. PRRs can be broadly divided into two groups; cytosolic receptors which consist of RIG-I-like receptors (RLRs) and NOD-like receptors (NLRs), and transmembrane receptors which consists of C-type lectin receptors (CLRs) and Toll-like receptors (TLRs) [27]. PRRs are expressed on both immune cells and nonimmune cells [27] and survey both intracellular and extracellular compartments, with each family controlling specific locations.

\subsection{Pattern recognition receptors (PRRs)}

The RLR family consists of retinoic acid-inducible gene-I (RIG-I), melanoma differentiation-associated gene 5 (MDA5) and laboratory of genetics and physiology 2 (LGP2) [27,28]. RLRs are essential for the recognition of both dsRNA and ssRNA viruses, therefore playing a role in antiviral innate immune responses. RIG-I has been identified in macrophages in human atherosclerotic lesions [29]. NLRs are composed of C-terminal leucine rich repeats, a central nucleotide binding domain and an N-terminal protein binding motif $[27,30]$. Only those NLRs which have caspase recruitment domains as their N-terminus, such as NOD1 and NOD2 promote transcription of pro-inflammatory mediators via NFKB [27]. TLRs and NODs act synergistically to promote pro-inflammatory cytokine production as they both recognise bacterial peptidoglycan components [31]. CLRs are unique in that they have a carbohydrate binding domain, which enables recognition of carbohydrates on pathogens. CLR activation can lead to production of pro-inflammatory cytokines or inhibition of TLR-mediated immune complexes [27].

\subsubsection{Toll-like Receptors (TLRs)}

TLRs are the most extensively studied and characterised PRRs. TLRs are type 1 transmembrane proteins with an ectodomain consisting of leucine rich repeats required to recognise PAMPs, a transmembrane domain which determines cellular localisation, and an intracellular tollinterleukin 1 receptor (TIR) domain needed for downstream signalling. At least 13 TLRs have been discovered thus far, each with a degree of specificity for various endogenous and exogenous ligands [32]. TLRs can be broadly divided into two categories; cell membrane TLRs (TLR1, TLR2, TLR4, TLR5, TLR6 and TLR11) and nucleic-acid sensing TLRs (TLR3, TLR7, TLR8, TLR9 and murine TLR13), which localise to intracellular vesicles including the endoplasmic reticulum, endosomes and lysosomes [4,33] (Fig. 2).

\subsubsection{TLR signalling pathways}

Upon recognition of PAMPs by TLRs, there is an upregulation of inflammatory gene transcription. Most TLRs form homodimers with the exception of TLR2 and TLR4. TLR2 forms a heterodimer with TLR1 or TLR6, while TLR4 forms a heterodimer with TLR6. TLR signalling is aided by the recruitment of five adaptor proteins to its TIR domain: myeloid differentiation primary-response protein 88 (MyD88), TIR domain-containing adaptor inducing IFN- $\beta$ (TRIF), TIR domaincontaining adaptor protein (TIRAP)/MyD88-adaptor-like (MAL), TRIF-related adaptor molecule (TRAM) and Sterile- $\alpha$ and armadillo motif-containing protein (SARM) [34]. The TLR signalling pathway is dependent on whether MyD88 or TRIF is recruited to the TIR domain.

4.1.2.1. MyD88-dependent signalling pathway. MyD88 consists of a death domain and a TIR domain. All TLRs, except TLR3, require the MyD88 dependent pathway to initiate downstream signalling. TLR2 and TLR4 utilise TIRAP/MAL as a bridge with MyD88. Following PAMP recognition by TLRs, MyD88 recruits members of the IL-1 receptor-associated kinase (IRAK) family. The IRAKs dissociate from MyD88 and associate with Tumour necrosis factor receptorassociated factor 6 (TRAF6), an E3 ubiquitin ligase to generate polyubiquitin chains [35]. Unconjugated K63-linked polyubiquitin chains activate a complex consisting of TAK1 and TAK-1 binding proteins (TAB)1, 2 and 3. This complex then translocates to the cytosol, where TAK1 phosphorylates IKK- $\beta$. Subsequently the IKK complex, consisting of IKK $\alpha$, IKK $\beta$ and NEMO, phosphorylates I $\mathrm{B} \alpha$, an NFKB inhibitory protein. Phosphorylated $\mathrm{I} \kappa \mathrm{B}$ is degraded by the ubiquitin proteosome system freeing NFKB to translocate into the nucleus and mediate transcription of inflammatory genes. TAK1 also phosphorylates MAPK6 which results in the activation of the MAPKs Erk1, Erk2, p38 and Jnk. Activation of the MAPK pathway results in the formation of activated protein (AP)-1, a transcription factor complex controlling many genes encoding cytokines.

4.1.2.2. TRIF-dependent signalling pathway. TLR3 recognises dsRNA and utilises signalling via TRIF which culminates in IRF3 and NFKB activation [36]. TRIF associates with TRAF3 and TRAF6 via its N-terminal TRAF binding-motifs. TRAF3 activates TBK1 and IKKE which phosphorylate IRF3 enabling its translocation into the nucleus [37,38]. IRF3 mediates the production of proinflammatory cytokines, type 1 IFNs and subsequently IFN-induced genes. The TNFR-associated death domain protein (TRADD) is involved in TRIF dependent signalling. A complex is formed consisting of TRADD, FADD and RIP1. TRADD triggers the ubiquitination of RIP1 which leads to NFKB activation. In addition, TRIF associates with TRAF6 to activate TAK1. This is thought to occur in an ubiquitination dependent manner resulting in phosphorylation of the inhibitory molecule IKB $\alpha$ by IKK- $\alpha$ and IKK- $\beta$ [36].

TLR4 is unique in that it utilises both the MyD88 and TRIF dependent pathways. It appears that the receptor's cellular localisation determines which pathway occurs $[39,40]$. First, upon ligand binding membrane bound TLR4 recruits MyD88 which binds to MAL to activate NFKB and MAPK. Secondly, TLR4 is translocated to the endosome via dynamin dependent endocytosis. There TLR4 associates with TRAM to trigger the TRIF dependent pathway resulting in IRF3 activation and late phase activation of NFKB and MAPK [39-41].

\subsubsection{Toll-like receptor ligands}

TLRs respond to a variety of exogenous (PAMPs) and endogenous (DAMPs) ligands (Fig. 2). Various ligands are present in the atherosclerotic lesion and may elicit responses in the plaque. Heterodimerisation 


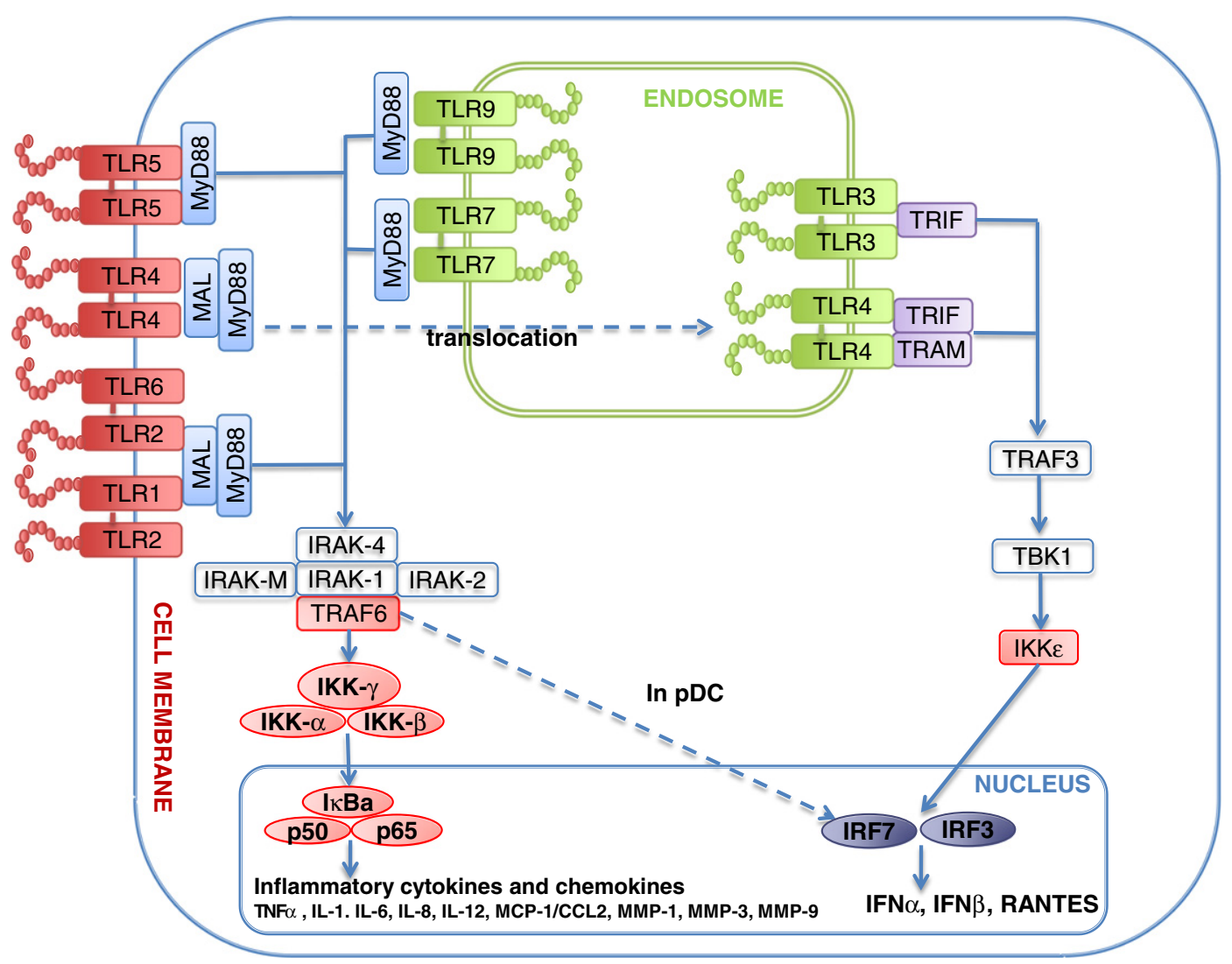

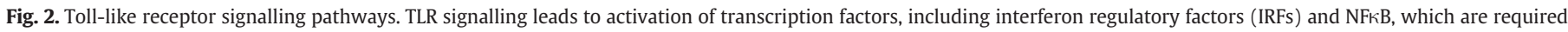

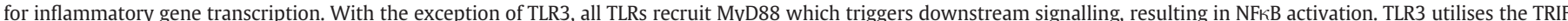

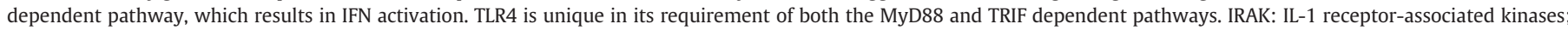

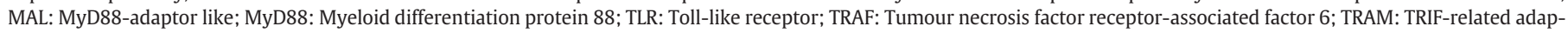
tor molecule; TRIF: TIR domain-containing adaptor inducing interferon- $\beta$.

of TLR2 with TLR1 or TLR6 increases its specificity enabling discrimination between different ligands [42-45]. Further specificity of TLR action has been reviewed by Piccinini and colleagues where they highlight that homo- or heterodimerisation along with co-receptors and accessory molecules confer specificity to ligand detection [46]. In addition, they identify that DAMPs and PAMPs act in a disparate manner requiring different co-receptors and accessory molecules. Thus complete elucidation of these differing mechanisms could enable targeting of inappropriate, pathogenic inflammation (Fig. 3).

Various PAMPs have been identified in atherosclerotic plaques and exist in the form of bacterial signatures including nucleic acids, peptidoglycans and exogenous heat shock proteins (HSPs). Several DAMPs have also been identified. They include lipoproteins, material from necrotic cells and extracellular matrix proteins. HSPs are released from necrotic cells and trigger proinflammatory cytokine production in a TLR2- and TLR4-dependent manner $[47,48]$. HSPs have been identified as possible autoantigens involved in (auto)immunological injury in the vessel wall, thought to help initiate atherosclerosis $[49,50]$.

Lipids also act as extracellular ligands. Saturated fatty acids stimulate TLR4 and promote gene expression whilst polyunsaturated fatty acids inhibit TLR4 activation [51]. MmLDL can act in two ways; it can involve macrophages and endothelial cells via a CD14/TLR4/MD-2 mechanism which is MyD88 dependent; or it can induce reactive oxygen species production in macrophages via TLR4 in a MyD88 independent manner [52,53]. Oxidised LDL and $\beta$-amyloid peptide stimulate the TLR4/6 heterodimer - which requires the scavenger receptor CD36 to promote inflammatory gene expression [54].

\subsubsection{Expression of TLRs in atherosclerosis}

TLRs are expressed by a range of cells including leukocytes, dendritic cells (DCs), and T and B lymphocytes (reviewed in [55]). Edfeldt and colleagues demonstrated TLR1, TLR2 and TLR4 are increased in human atherosclerotic plaques and several TLR-expressing cells are activated [56]. The expression of TLRs on innate immune cells in relation to atherosclerosis will be detailed later.

T lymphocytes (both $\mathrm{CD}^{+}$and $\mathrm{CD}^{+}$) are present in atherosclerotic lesions in both humans and murine models. T-cell clones in human atherosclerotic plaques are immunospecific for self antigens such as oxidised LDL [57]. Differences occur in TLR expression across T lymphocyte subsets and their locations, which reflect their specialised immune functions [55]. B lymphocytes express TLRs both at the mRNA and protein level. Human B cells express TLR1, TLR6, TLR7, TLR9 and TLR10 [58-61]. TLR expression appears to depend on location and maturity of B lymphocytes but discrepancies exist in the literature regarding expression of TLRs on B lymphocytes in humans [62]. Murine expression on B lymphocytes is also very wide ranging but differences exist in comparison to human expression [63-65]. For example, in contrast to humans, TLR expression does not differ between murine naïve B cells and memory B cells [64].

Interestingly, although TLRs are expressed by the aforementioned cell types, in atherogenesis the earliest expression of TLRs occurs in resident vascular cells [55]. There appears to be variation in the expression of TLRs across different vascular beds. TLR3 mRNA is found in the aorta and the temporal and iliac arteries express TLR8 mRNA, whilst the carotid artery expresses both TLR3 and TLR8 mRNA [66]. Human vascular SMCs constitutively express mRNA for TLR1, TLR3, 


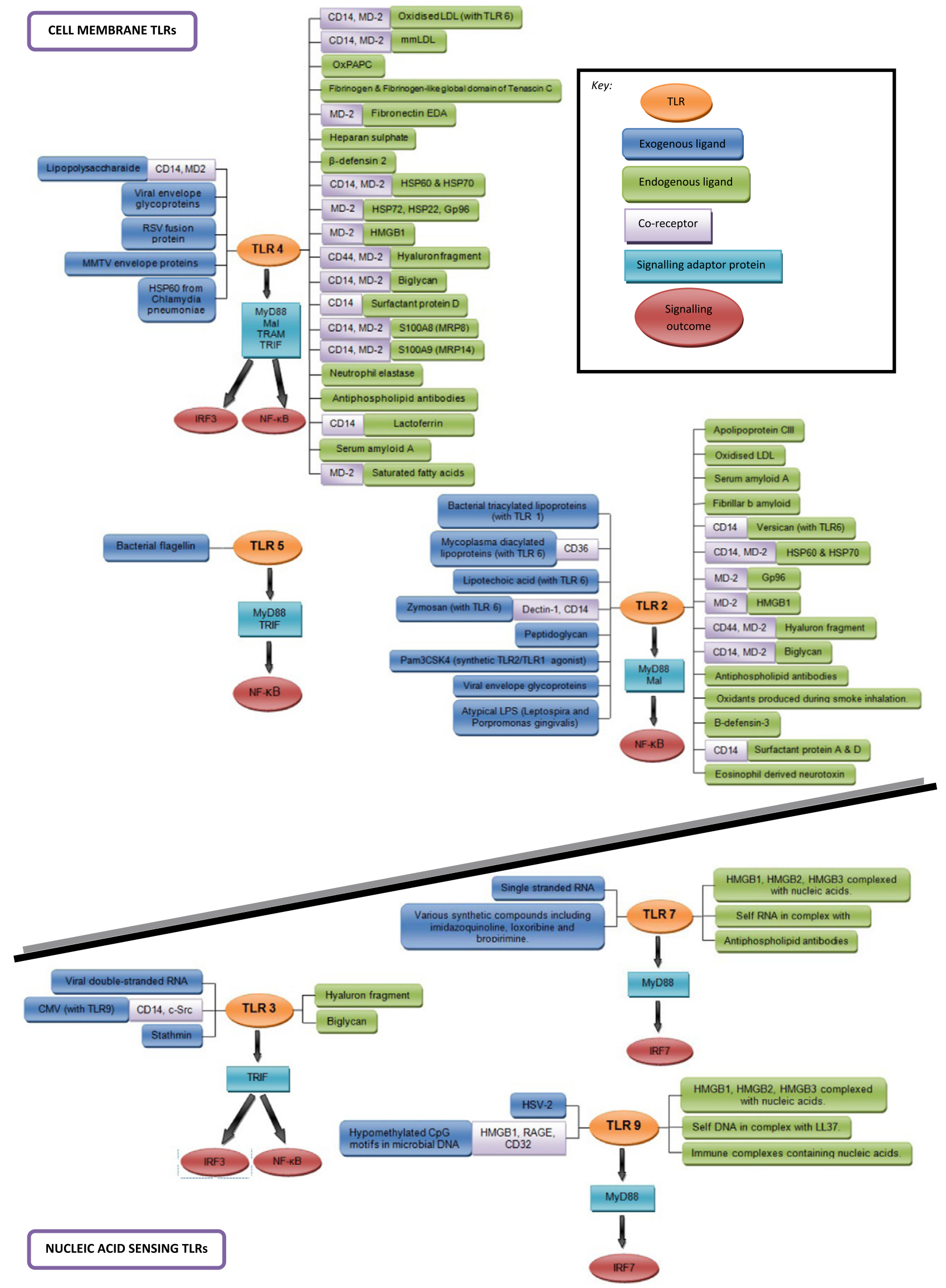

Fig. 3. Exogenous and endogenous ligands of Toll-like receptors. 
TLR4 and TLR6 [67]. TLR2 is constitutively expressed by murine aortic SMCs, whereas TLR2 expression can be induced in human coronary artery SMCs by Chlamydia Pneumonia, TLR3 and TLR4 ligand stimulation [68].

\subsubsection{Role of TLRs in atherosclerosis}

TLRs can directly affect atheroma formation as stimulation of macrophages with TLR2, TLR4 and TLR9 ligands promote lipid uptake $[69,70]$. Recently, experimental evidence using $\mathrm{ApoE}^{-1-}$ mice showed that TLR4 and TLR2, albeit to a lesser extent, contribute to early stage intimal foam cell accumulation in the aorta at sites susceptible to lesion formation [71]. TLR4 can stimulate macropinocytosis of lipids in differentiated macrophages [72]. Increased lipid uptake can also be mediated by increased expression of scavenger receptors induced by TLR3, TLR4 and TLR9 [69,73]. TLRs and their ligands can also disrupt cholesterol efflux mechanisms, which can contribute to foam cell formation.

TLR2 expression is increased in endothelial cells at atherosclerosis prone sites such as the inner curvature of the aortic arch in $\mathrm{LDLR}^{-/-}$ mice; such expression is associated with early atherosclerosis [74]. However, bone marrow transfer from $\mathrm{TLR}^{-1-}$ mice to $\mathrm{LDLR}^{-/-}$ mice had no effect on lesion formation [75]. In contrast, bone marrow transfer prior to $\mathrm{Pam}_{3} \mathrm{CSK}_{4}$ (synthetic TLR2 agonist) stimulation caused a decrease in lesion development, suggesting that perhaps exogenous agonists induce pro-atherogenic TLR2 signalling via myeloid cells, whereas non-myeloid cells detect endogenous agonists. ApoE $^{-/-}$mice deficient in TLR4 and TLR2 displayed a 55\% decrease in atherosclerotic lesion development, whilst a $65 \%$ decrease in macrophage infiltration was seen in $\mathrm{ApoE}^{-1-}$ mice deficient in TLR4 [75,76]. In the absence of TLR2 and TLR4, decreased lesion size was mirrored by a decrease in peripheral CCL2 levels; a chemokine that is critical for monocyte recruitment to atherosclerotic plaques [77].

We have investigated the influence of endosomal TLRs on atherosclerosis and arterial injury using both human and murine models of atherosclerosis. Contrary to the initial belief that TLRs are purely proatherogenic, we recently reported an unexpected protective role for TLR3 in arterial injury and atherosclerosis [78]. ApoE ${ }^{-/-}$mice with a TLR3 deficiency have an accelerated onset of atherosclerosis while intraperitoneal administration of Poly(I:C) - a TLR3 agonist - reduces neointimal formation. Moreover, genetic deletion of TLR3 correlates with numerous large breakages of the elastic lamina after placement of an arterial injury-inducing perivascular collar. This data demonstrates for the first time that while cell surface TLRs may promote atherosclerosis, intracellular TLRs protect against hypercholesterolemia and injury-induced lesions. Lesion development in both humans and mice associates with increased expression of TLR3 and TLR3associated responses, particularly in SMCs which maybe a protective cell type.

It is unknown what endogenous agonists of TLR3 may be involved in protection, as its genetic removal exacerbates atherosclerosis and damage to the elastic lamina. Interestingly stathmin, which is upregulated upon brain injury and participates in microtubule assembly, is described as a candidate TLR3 agonist, linked to the induction of a neuroprotective gene profile [79].

The mechanism of TLR3-induced protection is currently unknown it may relate to its preference for intracellular signalling via TRIF over MyD88 when compared to other TLRs. IFN $\beta$ production - as a result of TLR3 dependent signalling - is linked to reduced inflammasome activation, IL-1 signalling, and IL-10 induction [80]. However, it is uncertain whether the vasculoprotective effect of TLR3 is mediated by IFN $\beta$. Although an arterial injury model shows IFN $\beta$ to be protective [81], a more recent report showed a potentially deleterious role in atherosclerosis induced by hyperlipidaemia [82]. Synthetic dsRNA may not be safe as a therapeutic tool, as its administration elicits both pro-inflammatory and anti-inflammatory mediators [78]. A recent study showed that intravenous administration of dsRNA at high doses may lead to endothelial cell apoptosis and increased vascular lesion formation [83]. TLR3 activation in the vasculature can elicit the production of IL10 [78] and the B7 family members PDL1 and PDL2, which contribute to vascular protection [84]. Blocking the PD1-PDL1 interaction accelerates arterial disease in cardiac allografts [85].

\subsection{Activation of innate immune cells by TLRs in atherosclerosis}

\subsubsection{Mast cells}

Mast cells are found in connective tissues and are important for alerting the immune system to local infection. Derived from common myeloid progenitors, they play a prevalent role in allergic reactions, releasing proteins such as histamine, and sustaining inflammation. Mast cells have been observed in coronary and carotid artery plaques; specifically localised at sites of plaque erosion, haemorrhage or rupture [86]. They can secrete pro-inflammatory cytokines and serine proteases, such as chymase, which can activate proteases and MMPs promoting plaque instability, and the conversion of angiotensin I to angiotensin II [87]; promoting vasoconstriction and possibly restricting arterial wall remodelling. Mast cells also contribute to intraplaque haemorrhage, macrophage apoptosis and the recruitment of leukocytes to murine atherosclerotic plaques via the CXCR2/VLA-4 axis [88]. It is thought that substance $P$ causes adventitial mast cell activation and intraplaque haemorrhage via TLR2 upregulation, suggesting that TLR2 plays a role in the vulnerable plaque phenotype [88]. Human and rodent mast cells have been identified to express TLR1-TLR7 and TLR9 [89].

\subsubsection{Dendritic cells}

Dendritic cells (DCs) are vital for priming innate and adaptive immune responses with their antigen presenting capabilities, while maintaining self tolerance. DCs exist as one of two subsets: conventional (cDCs) or plasmacytoid (pDCs). cDCs can be subdivided into myeloid (mDCs) and lymphoid (IDCs), and are primarily responsible for antigen presentation and priming of naïve T lymphocytes while pDCs secrete large amounts of interferons. Immature DCs encounter pathogens in peripheral tissues activating TLR signalling which triggers DC maturation. DCs then migrate to lymphoid tissues; express MHC and co-stimulatory molecules, and prime naïve $\mathrm{T}$ cells in the T-cell zones.

$\mathrm{CD}_{11 \mathrm{C}^{+}}$DCs accumulate at vascular regions predisposed to atherosclerosis correlating with increased expression of VCAM-1 [90]. Mature DCs are observed more frequently in advanced lesions. High expression of HLA-DR (MHC-II) and interactions with T cells are particularly evident in rupture-prone regions of the plaque [91]. A deficiency in the fractalkine receptor $\mathrm{CX}_{3} \mathrm{CR} 1$ in the aorta impairs the accumulation of dendritic cells in the intima [92], suggesting they may differentiate from Ly-6C ${ }^{\text {lo }}$ monocytes which normally express high levels of $\mathrm{CX}_{3} \mathrm{CR}$. OxLDL acts as an antigen upregulating DC expression of HLA-DR and its co-stimulatory molecules, in parallel with an increase in T cell proliferation [93]. DCs express scavenger receptors - namely LOX-1, CD36 and CD205 - which mediate their uptake of oxLDL activating the NFkB pathway, and maturation into DCs with a pro-inflammatory cytokine profile [94]. DCs may become activated by oxLDL in the plaque, migrate to secondary lymphoid organs and prime the clonal expansion of oxLDL-specific T cells.

cDCs express TLR2-8 while pDCs express TLR7 and TLR9. In contrast to mDCs, pDCs strongly express TLR7 and TLR9 mRNA but only weakly express TLR2 and TLR4 mRNA [95]. However, both subtypes respond to stimulation with the TLR7 ligand R848; but in response, pDCs express IFN- $\alpha$ whilst mDCs express IL-12 [96]. TLR7 and TLR9 induce the production of type 1 IFNs and NFKB dependent cytokines via the MyD88 dependent pathway. pDCs constitutively express IRF7 which binds to MyD88 and forms a complex with IRAK1, IRAK4, TRAF3, TRAF6 and IKK $\alpha$ [28]. Phosphorylated IRF7 translocates into the nucleus where it facilitates the production of type 1 IFNs. In contrast, $c D C s$ mediate the activation of IRF1 resulting in IFN- $\beta$ gene 
expression $[97,98]$. Severe hypercholesterolaemia inhibits the TLRinduced production of pro-inflammatory cytokines by DCs, by inhibiting the nuclear translocation of NFKB; subsequently Th1 responses are diminished while Th2 responses are enhanced [99]. These studies collectively suggest pro-inflammatory Th1 responses are predominant in moderate hypercholesterolaemia while a shift to Th2 responses occurs in severe hypercholesterolaemia [100].

\subsubsection{Monocytes}

Monocytes are derived from macrophage-DC precursors in the bone marrow. They constitute $5-10 \%$ of peripheral blood leukocytes [101] and can circulate for several days before entering tissues via the leukocyte adhesion cascade and differentiating into macrophages. A deficiency in adhesion molecules such as P-selectin, ICAM- 1 and VCAM-1, or blockage of their interactions with their respective ligands can reduce monocyte recruitment and atherosclerotic lesion size $[102,103]$.

Mature murine monocytes have been classified into two main subsets according to their expression levels of Ly-6C, the chemokine receptors CCR2 and $\mathrm{CX}_{3} \mathrm{CR} 1$. Ly- $6 \mathrm{C}^{\text {high }} \mathrm{CCR} 2{ }^{\text {high }} \mathrm{CX}_{3} \mathrm{CR} 1^{\text {low }}$ monocytes termed inflammatory or classical monocytes - typically home to inflamed sites, with the ability to respond to MCP-1 [104], and secrete pro-inflammatory cytokines. They represent $90 \%$ of the monocytes that accumulate in murine atherosclerotic lesions. Hypercholesterolaemia increases the proliferation and differentiation of Ly- $6 \mathrm{C}^{\text {high }}$ monocytes and macrophage foam cell formation, while impairing conversion to resident subsets [105].

Ly-6C ${ }^{\text {low }} C C R 22^{\text {low }} \mathrm{CX}_{3} \mathrm{CR} 1^{\text {high }}$ monocytes - termed resident or nonclassical monocytes - patrol the endothelium under homeostatic conditions, relying on LFA- 1 and $\mathrm{CX}_{3} \mathrm{CR} 1$ for crawling and extravasation [106]; with the ability to rapidly invade infected sites and initiate an immune response. $\mathrm{CX}_{3} \mathrm{CR} 1$ seems important for their survival as the anti-apoptotic gene Bcl-2 is not expressed in $\mathrm{CX}_{3} \mathrm{CR} 1$-deficient resident monocytes [107]. Enforcing the survival of monocytes in $\mathrm{CX}_{3} \mathrm{CR}$ 1-deficient mice restores atherogenesis [108] while inhibiting Fractalkine $\left(C_{3} C L 1\right)$ stabilises LSS-induced plaques [109]. CX $_{3} C R 1-$ deficient mice have reduced lesions and macrophage accumulation while retaining the characteristics of stable plaques [110]. The number of circulating Ly-6C $\mathrm{C}^{\mathrm{lo}}$ monocytes correlates with lesion size [111]. This could be explained by the capability of resident monocytes to become loaded with cholesterol by binding to circulating oxLDL in both humans and mice [112,113]. Therefore Ly-6C $C^{\text {lo }}$ monocytes may be a significant source of lipids in early atherosclerotic plaques [104]. Resident monocytes are reduced in plaques but are less inflammatory and may promote stable plaque formation in the latter stages of atherosclerosis [114].

Inflammatory and resident monocytes exist approximately at a 1:1 ratio in the blood of mice [115]. One study showed Ly- $6 \mathrm{C}^{\mathrm{lo}}$ monocytes are a more mature form of monocytes [116] while other studies show little conversion of Ly-6C ${ }^{\text {hi }}$ to Ly- $6 C^{\text {lo }}$ monocytes [117]. A mouse model of myocardial infarction demonstrated that Ly- $6 \mathrm{C}^{\mathrm{hi}}$ monocytes dominate the early stages phagocytosing damaged tissue while Ly$6 \mathrm{C}^{\mathrm{lo}}$ monocytes promote healing and angiogenesis in the latter stages [117]. Inflammatory monocytes use the chemokine receptors $C_{3}$ CR1, CCR2 and CCR5 to enter plaques while resident monocytes use CCR5 only [118]. Ly-6C ${ }^{\text {hi }}$ monocytes seem dependent on CCR2 for their mobilisation from bone marrow and tissue infiltration [111,119]. Additive inhibition of CCL2, CX ${ }_{3}$ CR1 and CCR5 virtually abolishes atherosclerosis and monocyte accumulation, while exhibiting a halt in bone marrow and blood monocytosis [111].

In humans, $\mathrm{CX}_{3} \mathrm{CR} 1$ is expressed at low levels on classical CD14 ${ }^{\text {hi }} \mathrm{CD} 16^{-}$monocytes while nonclassical $\mathrm{CD} 14^{\text {low }} \mathrm{CD} 16^{+}$monocytes (normally excluded from inflamed tissues) express high amounts of $\mathrm{CX}_{3} \mathrm{CR} 1$ [115]. CD14 is a co-receptor for TLR4 enabling lipopolysaccharide detection while CD16 (or FC $\gamma$ RIII) belongs to the Fc $\gamma$ receptor family that binds antibodies during immune responses such as antibody-dependent cell-mediated cytotoxicity. Approximately $90 \%$ of circulating monocytes in humans belong to the classical subset [104]. The amount of pro-inflammatory $\mathrm{CD} 14^{+} \mathrm{CD} 16^{+}$ monocytes and serum TNF- $\alpha$ levels is elevated in patients with coronary artery disease [120], and this monocyte subset negatively correlates with fibrous cap thickness [121]. While CCR2 and $\mathrm{CX}_{3} \mathrm{CR} 1$ are similarly expressed between human and mouse monocyte subsets, there are differences in the expression of other genes between the two species, such as the macrophage scavenger receptor [122], which can make the determination of human monocytic behaviour difficult when based on murine studies.

Studies of monocyte subsets in mouse models of the peritoneal infection Leishmania monocytogenes and myocardial infarction suggest Ly-6C $\mathrm{C}^{\text {hi }}$ monocytes differentiate into classical M1-type macrophages and dendritic cells with a pro-inflammatory transcriptional programme, while Ly- $6 \mathrm{C}^{\mathrm{lo}}$ monocytes differentiate into M2 macrophages of an alternatively activated phenotype exhibiting tissue repair activity $[106,117]$. However in vitro studies suggest monocytes are very plastic. GM-CSF differentiates monocytes into dendritic cells [123] while M-CSF promotes macrophage development regardless of the monocyte subset present. Another transcriptome-level study showed an upregulation of M1 macrophage-associated genes following GMCSF-driven differentiation of human monocytes while M2 macrophage-associated genes are activated in response to M-CSFdriven differentiation [124].

\subsubsection{Macrophages}

Macrophages are differentiated cells within tissues derived from monocytes or directly from myeloid progenitor cells during haemopoiesis [125]. Macrophages recognise PAMPs via various cell surface receptors e.g. TLRs and scavenger receptors. Inflammatory stimuli increase the expression of certain macrophage receptors like PRRs augmenting their immune behaviour relating to clearance of bacteria and their cytokine equilibrium [126] (Fig. 4).

Gordon et al. proposed a paradigm of macrophage activation to include 4 stages: differentiation by growth factors such as GM-CSF and M-CSF, priming by IFN- $\gamma$ or IL- 4 and IL-13, activation into a functional phenotype from a TLR stimulus for example, and finally deactivation to enable repair functions by anti-inflammatory mediators like IL-10 and TGF- $\beta$ [127]. The differentiation of monocytes into macrophages is essential for the development of atherosclerotic lesions; for example M-CSF-deficient mice are resistant to the development of atherosclerosis [128].

Macrophages are extremely plastic and capable of modifying their behaviour upon microenvironmental cues; as a result a dichotomy is believed to exist in parallel with the Th1 and Th2 lymphocyte subsets. In response to bacterial motifs (e.g. LPS) and IFN- $\gamma$, macrophages undergo "classic activation"; a type of priming that mirrors Th1 lymphocytes [129] and can aid the resolution of infection and tumour resistance. Adaptive immunity, such as IFN- $\gamma$ production by Th1 cells, maintains the classical phenotype strengthening defence against intracellular microorganisms [130]. LPS or IFN- $\gamma$ primed macrophages, also termed M1, are considered IL-12 ${ }^{\text {high }}$ IL- $10^{\text {low }}$ [131]. They are integral to Th1 responses killing microorganisms and tumour cells while secreting pro-inflammatory cytokines. Th1 responses may drive atherosclerosis as inactivation of the transcription factor T-bet which promotes T cell development - reduces MHC-II expression by macrophages in atherosclerosis [132].

Alternative macrophage activation (or M2) was first identified upon exposure to IL-4 [127]. IL-4 and IL-13 increase expression of the decoy IL-1RII and the IL-1R antagonist (IL-1Ra) inhibiting IL-1. M2 macrophages fine tune Th2 responses and adaptive immunity; clear cell debris via their scavenger receptors; promote tolerance, tissue remodelling and repair [131]. Some intracellular pathogens are able to exploit mannose and scavenger receptors and induce an alternatively activated phenotype enabling their survival and replication 


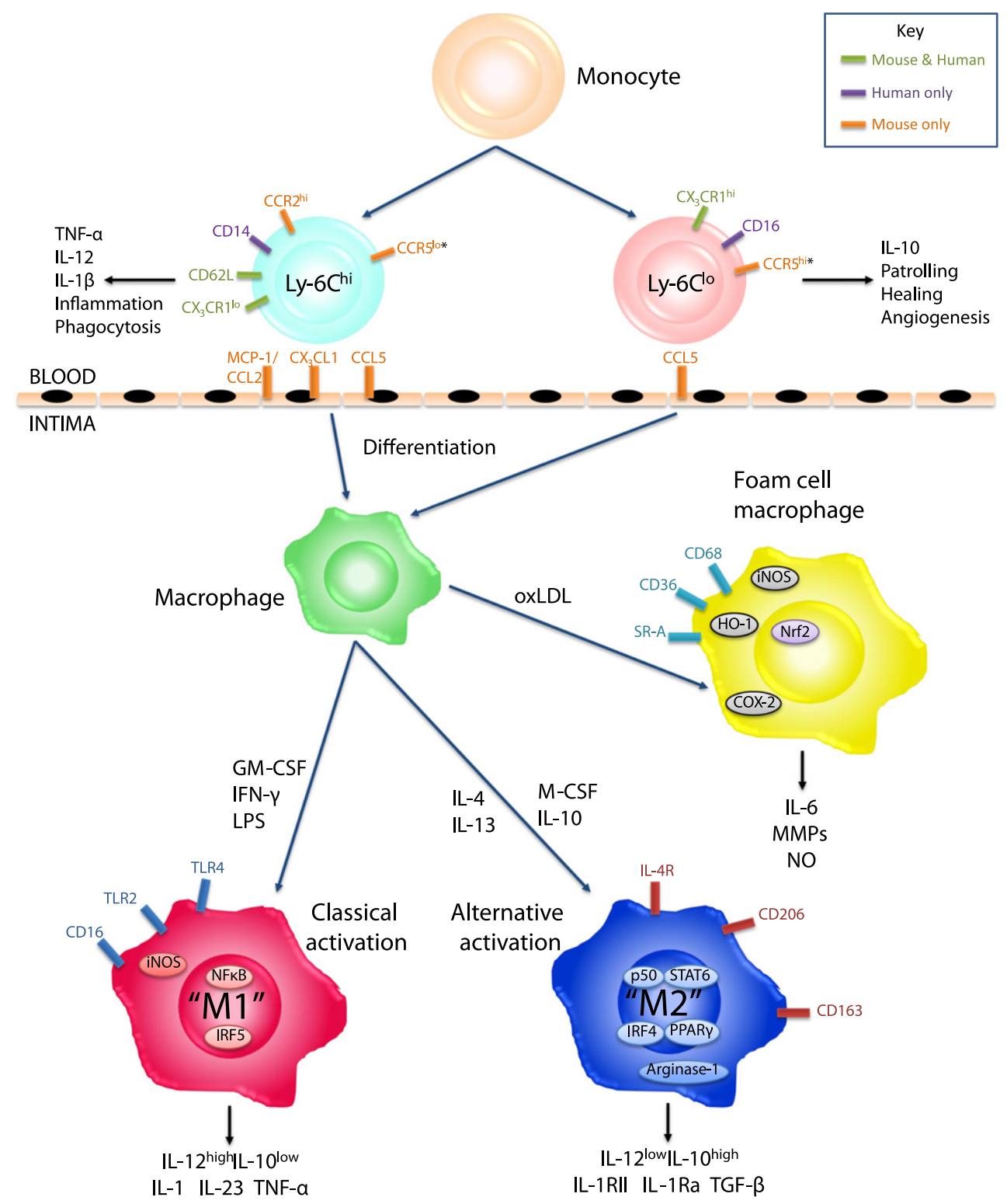

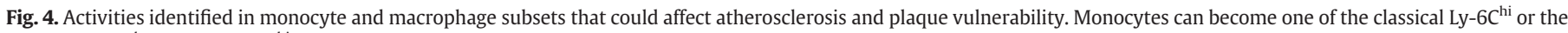

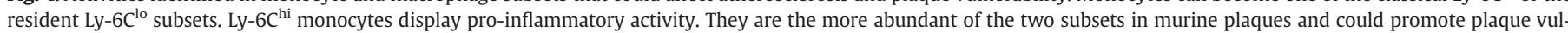

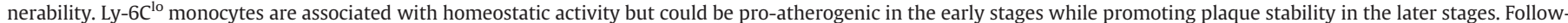

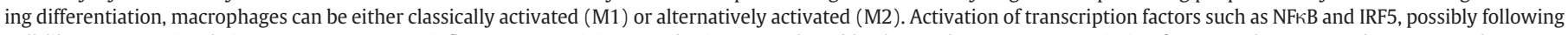

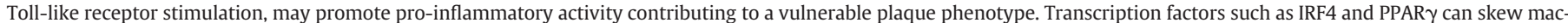

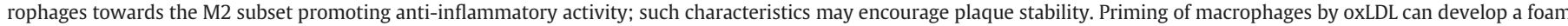

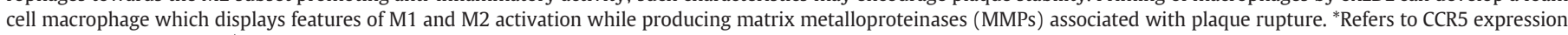
levels observed in $\mathrm{ApoE}^{-1-}$ mice.

within the host macrophage [133]. M2 polarising signals like IL-4 and IL-10 are able to inhibit pro-inflammatory chemokine expression by inhibiting STAT1 and NFKB [134]. The p50 subunit of NFKB regulates M2-associated gene expression while inhibiting M1 polarisation and IFN- $\beta$ production [135]. Murine M2 macrophages express increased levels of arginase-1; an enzyme responsible for synthesising proline, a key component of collagen, and polyamine precursors important for cell growth [136]. In vitro studies suggest regulatory T lymphocytes and M2 macrophages drive each other's differentiation reciprocally $[137,138]$.

M2 macrophages are heterogeneous and Mantovani et al. proposed that they exist as one of three subtypes generated by different inflammatory and opsonic signals: M2a macrophages induced by IL- 4 or IL-13, M2b by exposure to immune complexes, IL-1R or TLR agonists, or M2c activated by glucocorticoid hormones or IL-10 [131]. M2a and
M2c macrophages display increased activity of the arginase pathway demonstrated by expression of arginase- 1 by murine macrophages. While M2a and M2c macrophages are considered IL- $12^{\text {low }}$ IL- $10^{\text {high }}$, M2b macrophages express high levels of both cytokines while promoting Th2 cell differentiation and regulating inflammation [139].

The widely used M1-M2 nomenclature describing macrophages could be premature; macrophages may instead exist as a continuum. A recent review by Mosser and Edwards suggested a spectrum of macrophage activation which can be categorised according to three different functions: host defence, wound healing and immune regulation [130]. The macrophage's phenotype could also be dependent on which tissue it is localised to [140].

Lipids are known to affect macrophage activation patterns [127]. Macrophages residing in the adipose tissue of lean mice express markers of M2 macrophages while adipose tissue macrophages 
from obese mice upregulate M1 macrophage markers and contribute to insulin resistance; an effect which is abolished by the knockout of CCR2 or expression of IL-10 [141], and is also observed in humans [141]. CD11 ${ }^{+}$macrophages from adipose tissue of obese mice have increased expression of several M1 and M2 genes [142]. As previously mentioned the CD36 and SR-A scavenger receptors enable lipid uptake by macrophages and are deemed proatherogenic [143]. A recent study demonstrated that blockage of oxLDL with an Fc-CD68 fusion protein increased the collagen content of plaques, reduced plaque extension, spontaneous ruptures, and infiltration by $\mathrm{T}$ lymphocytes and macrophages in $\mathrm{ApoE}^{-/-}$mice [144], thereby possibly stabilising plaques. As CD68 is an oxLDL binding receptor, it may cooperate with other scavenger receptors to facilitate lipid uptake.

Foam cells display decreased expression of arginase-1, while increasing production of MMP12 and nitric oxide. These patterns were particularly evident close to the lipid core [145] and maybe advancing atherosclerosis. MMP14 ${ }^{\text {high }}$ TIMP $3^{\text {low }}$ foam cells - which are stimulated by pro-inflammatory cytokines - proliferate and invade very readily but undergo apoptosis amid LPS or starvation challenge [146]. These characteristics may aid formation of the lipid necrotic core where these cells were most frequently observed. MMP upregulation and TIMP downregulation may be responsible for collagen degradation in the core and fibrous cap of advanced plaques. Oxidised phospholipids within atherosclerotic plaques can downregulate M1 and M2 gene expression, and are proposed to induce a Mox macrophage phenotype associated with Nrf2-mediated expression of redox-regulatory genes, such as haem oxygenase-1 [142]. It has been hypothesised that foam cells, derived from recently recruited macrophages, may possess an immature phenotype matching neither M1 nor M2 macrophages, while mature foam cells display features of classical and alternative activation [147].

Macrophage heterogeneity may play an important role in lesion development and outcome [148]. Interestingly, M2 macrophages accumulate first in murine atherosclerotic lesions, while lesion progression correlates with the predominance of M1 over M2 macrophages [136]. It appears inflammatory cytokine-induced M1 macrophages are associated with disease progression so agonists of the PPAR $\gamma$ receptor, which induces arginase- 1 expression enhancing the M2 phenotype, could stabilise plaques. Both IFN- $\gamma$ and TLR4 have already been implicated in M1 polarisation [149], and their genetic deletion reduces atherosclerosis development [76]. C-reactive protein (CRP), an acute-phase protein widely regarded as a marker of systemic inflammation and cardiovascular risk, was recently demonstrated to induce monocytic differentiation and the conversion of M2 macrophages into M1 macrophages via NFKB, upon binding to the CD32 and CD64 Fc $\gamma$ receptors [150]. Haemoglobin-haptoglobin complexes present in plaques following intraplaque haemorrhage promote the differentiation of monocytes into atheroprotective M2-like macrophages, identified by their expression of CD163 [151].

\subsubsection{Are TLRs critical for macrophage polarisation and activation in atherosclerosis?}

As described earlier, CD14 is an important marker to discriminate between the monocyte subsets in humans. CD14 is also a co-receptor for TLR4, which activates intracellular signalling cascades such as MyD88-dependent signalling, and NFKB and is already implicated in M1 macrophage polarisation [149]. Hence TLRs could be pivotal in the polarisation of macrophages. Short-term culture of mixed cell populations from human carotid endarterectomies implicated a role for NFKB in the regulation of pro-inflammatory genes such as TF, IL6 , IL-8, TNF- $\alpha$ and several MMPs [152]. NFkB has been implemented in the transcription of the M1 markers iNOS and COX-2 [153,154]. M1 macrophages primed by IFN- $\gamma$ upregulate the expression of TLR4 and components of the MyD88 signalling pathway. Detection of LPS by TLR4 in synergy with CD14, stimulates NFKB-dependent transcription of inflammatory chemokines e.g. CXCL8 (IL-8) and CCL2 (MCP-1) [155].

TLR2 is more highly expressed on human $\mathrm{CD}_{1} 6^{+}$monocytes being further enhanced by M-CSF and IL-10 [156]. Necrotic cells but not apoptotic cells can activate NFkB inducing the expression of proinflammatory and tissue repair genes by macrophages in a TLR2dependant manner [157]. A deficiency in IKK $\beta$ - an inhibitor of $\mathrm{NF} \kappa \mathrm{B}$ - increases expression of pro-inflammatory cytokines and the M1 marker iNOS while diminishing the M2 markers arginase-1 and IL-4R [158]. But mycobacterial infection can induce expression of arginase- 1 by classically activated macrophages in a TLR-dependent manner [159]. A previous review suggested exposure of monocytes to TLR agonists may prime them into M2b macrophages [131], which share some characteristics with M1 macrophages. However the binding of immune complexes to M2b macrophage Fc $\gamma$ receptors inhibits TLR4 and type I interferon signalling [160].

One set of transcription factors that is activated by TLR signalling is the interferon-regulatory factor (IRF) family. During helminth infection, IRF4 was shown to skew macrophage polarisation towards the M2 subset [161]. The knockout of another family member IRF5 in mice causes defective pro-inflammatory cytokine and type I interferon production [162]. IRF4 inhibits IRF5 from binding to MyD88, while in a model of Epstein-Barr viral infection, IRF4 can bind directly to the promoter of IRF5 [163]. Thus IRF4 acts as a negative feedback mechanism mitigating inflammatory cytokine production [164].

\subsection{TLRs as therapeutic targets}

With increasing evidence of TLRs playing significant roles in atherosclerosis, they may provide a potential alternative for therapeutic targets in atherosclerosis. It was previously thought that antagonists of TLRs, namely TLR2 and TLR4, are the main pathway for treatment in atherosclerosis. We have recently shown the possibility of promoting TLRs in combating atherosclerosis [78]. However, obstacles still exist with regards to translational medicine due to differences between human and murine immune systems, including the cellular expression patterns of TLRs. In addition, it is also essential to identify the optimal timing of intervention. Albeit, given the contribution of TLRs in mediating atherosclerosis, therapeutic targeting of TLRs by drugs could have massive clinical implications in combating atherosclerosis, which is proving to be a major threat to human health globally.

\section{Conclusions}

Recent evidence suggests a prominent role for innate immune responses in the pathogenesis of atherosclerosis. Upon recognition of PAMPs by TLRs, there is an upregulation of inflammatory gene transcription. Various PAMPs and DAMPs are present in the atherosclerotic lesion and may elicit responses in the plaque. Many TLRs - most notably TLR1, TLR2 and TLR4 - are upregulated in atherosclerotic vessels and contribute to lesion formation, while TLR3 appears to be atheroprotective. Innate immune cells play a significant role in atherogenesis and in shaping the plaque's phenotype; those displaying a pro-inflammatory phenotype, especially the abundant macrophages, are associated with plaque vulnerability. Such proinflammatory activity triggered by TLR stimulation maybe a key factor in promoting the development of high-risk atherosclerotic lesions such as TCFAs. Lipids, growth factors and cytokines have been shown to contribute to the polarisation of macrophages towards a particular phenotype; classically activated M1 macrophages could promote plaque vulnerability while alternatively activated M2 macrophages may promote plaque stability. As TLRs and their downstream transcription factors have demonstrated a critical role in determining the inflammatory activity of macrophages, this axis serves as a potentially strong therapeutic target and could curtail lesion progression or promote plaque stability in the advanced stages. 


\section{Acknowledgements}

Anusha Seneviratne is funded by the British Heart Foundation as part of the British Heart Foundation (BHF) Centre of Research Excellence at Imperial College London. Dr Claudia Monaco has received funding from: the British Heart Foundation; European Commission under the 6th Framework Programme through the SME call for "Life sciences, genomics and biotechnology for health" (Contract number: LSHM-CT-2006-037400); European Collaborative Project on Inflammation and Vascular Wall Remodelling in Atherosclerosis Acronym: AtheroRemo; EU-HEALTH-2007-2.4.2-1. 2008; the Graham-Dixon Charitable Trust; the Kennedy Trustees. The Kennedy Institute of Rheumatology is funded by the Arthritis Research Campaign UK.

\section{References}

[1] Cardiovascular diseases (CVDs), World Health Organization. http://www.who. int/mediacentre/factsheets/fs317/en2011.

[2] Kannel WB, McGee D, Gordon T. A general cardiovascular risk profile: the Framingham Study. Am J Cardiol 1976;38(1):46-51.

[3] Ross R. Atherosclerosis - an inflammatory disease. N Engl J Med 1999;340(2): 115-26.

[4] Cole JE, Mitra AT, Monaco C. Treating atherosclerosis: the potential of Toll-like receptors as therapeutic targets. Expert Rev Cardiovasc Ther 2010;8(11): 1619-35.

[5] Glass CK, Witztum JL. Atherosclerosis. The road ahead. Cell 2001;104(4):503-16.

[6] Hansson GK, Robertson A-KL, Söderberg-Nauclér C. Inflammation and atherosclerosis. Annu Rev Pathol 2006;1:297-329.

[7] Hazen SL. Oxidized phospholipids as endogenous pattern recognition ligands in innate immunity. J Biol Chem 2008;283(23):15527-31.

[8] Sanders M. Molecular and cellular concepts in atherosclerosis. Pharmacol Ther 1994;61(1-2):109-53.

[9] Felton CV, Crook D, Davies MJ, Oliver MF. Relation of plaque lipid composition and morphology to the stability of human aortic plaques. Arterioscler Thromb Vasc Biol 1997;17(7):1337-45.

[10] Feintuch A, Ruengsakulrach P, Lin A, et al. Hemodynamics in the mouse aortic arch as assessed by MRI, ultrasound, and numerical modeling. Am J Physiol Heart Circ Physiol 2007;292(2):H884-92.

[11] Libby P. Inflammation in atherosclerosis. Nature 2002;420(6917):868-74.

[12] Virmani R, Kolodgie FD, Burke AP, Farb A, Schwartz SM. Lessons from sudden coronary death: a comprehensive morphological classification scheme for atherosclerotic lesions. Arterioscler Thromb Vasc Biol 2000;20(5):1262-75.

[13] Cheng C, Tempel D, van Haperen R, et al. Atherosclerotic lesion size and vulnerability are determined by patterns of fluid shear stress. Circulation 2006;113 (23):2744-53.

[14] Davies MJ, Richardson PD, Woolf N, Katz DR, Mann J. Risk of thrombosis in human atherosclerotic plaques: role of extracellular lipid, macrophage, and smooth muscle cell content. Br Heart J 1993;69(5):377-81.

[15] Stone GW, Maehara A, Lansky AJ, et al. A prospective natural-history study of coronary atherosclerosis. N Engl J Med 2011;364(3):226-35.

[16] Fagerberg B, Ryndel M, Kjelldahl J, et al. Differences in lesion severity and cellular composition between in vivo assessed upstream and downstream sides of human symptomatic carotid atherosclerotic plaques. J Vasc Res 2010;47(3): 221-30.

[17] Davies MJ. Stability and Instability: Two Faces of Coronary Atherosclerosis: The Paul Dudley White Lecture 1995. Circulation 1996;94(8):2013-20.

[18] Naghavi M, Libby P, Falk E, et al. From vulnerable plaque to vulnerable patient: a call for new definitions and risk assessment strategies: Part I. Circulation 2003;108(14):1664-72.

[19] Caro CG, Fitz-Gerald JM, Schroter RC. Atheroma and arterial wall shear. Observation, correlation and proposal of a shear dependent mass transfer mechanism for atherogenesis. Proc R Soc Lond B Biol Sci 1971;177(46):109-59.

[20] Wentzel JJ, Janssen E, Vos J, et al. Extension of increased atherosclerotic wall thickness into high shear stress regions is associated with loss of compensatory remodeling. Circulation 2003;108(1):17-23.

[21] Stone PH, Coskun AU, Kinlay S, et al. Regions of low endothelial shear stress are the sites where coronary plaque progresses and vascular remodelling occurs in humans: an in vivo serial study. Eur Heart J 2007;28(6):705-10.

[22] Gijsen FJH, Wentzel JJ, Thury A, et al. Strain distribution over plaques in human coronary arteries relates to shear stress. Am J Physiol Heart Circ Physiol 2008;295(4):H1608-14.

[23] Foin N, Segers D, Mohri Z, et al. Haemodynamic effects of focal and diffuse coronary stenosis. In: Escaned J, Serruys PW, editors. Coronary stenosis: imaging, structure and physiology. Toulouse, France: PCR Publishing; 2010. p. 47-58.

[24] Dirksen MT, van Der Wal AC, van Den Berg FM, van Der Loos CM, Becker AE. Distribution of inflammatory cells in atherosclerotic plaques relates to the direction of flow. Circulation 1998;98(19):2000-3.

[25] Tricot O, Mallat Z, Heymes C, Belmin J, Lesèche G, Tedgui A. Relation between endothelial cell apoptosis and blood flow direction in human atherosclerotic plaques. Circulation 2000;101(21):2450-3.
[26] Bianchi ME. DAMPs, PAMPs and alarmins: all we need to know about danger. J Leukoc Biol 2007;81(1):1-5.

[27] Takeuchi O, Akira S. Pattern recognition receptors and inflammation. Cell 2010;140(6):805-20.

[28] Kawai T, Akira S. Toll-like receptor and RIG-I-like receptor signaling. Ann N Y Acad Sci 2008;1143:1-20.

[29] Imaizumi T, Yagihashi N, Kubota K, et al. Expression of retinoic acid-inducible gene-I (RIG-I) in macrophages: possible involvement of RIG-I in atherosclerosis. J Atheroscler Thromb 2007;14(2):51-5.

[30] Inohara, Chamaillard, McDonald C, Nuñez G. NOD-LRR proteins: role in hostmicrobial interactions and inflammatory disease. Annu Rev Biochem 2005;74: 355-83.

[31] Brodsky I, Monack D. NLR-mediated control of inflammasome assembly in the host response against bacterial pathogens. Semin Immunol 2009;21(4): 199-207.

[32] O'Neill LA. The interleukin-1 receptor/Toll-like receptor superfamily: 10 years of progress. Immunol Rev 2008;226:10-8.

[33] Kawai T, Akira S. The role of pattern-recognition receptors in innate immunity: update on Toll-like receptors. Nat Immunol 2010;11(5):373-84.

[34] Akira S, Uematsu S, Takeuchi O. Pathogen recognition and innate immunity. Cell 2006;124(4):783-801

[35] Xia Z-P, Sun L, Chen X, et al. Direct activation of protein kinases by unanchored polyubiquitin chains. Nature 2009;461(7260):114-9.

[36] Alexopoulou L, Holt A, Medzhitov R, Flavell R. Recognition of double-stranded RNA and activation of NF-KB by Toll-like receptor 3. Nature 2001;413(6857):732-8.

[37] Oganesyan G, Saha SK, Guo B, et al. Critical role of TRAF3 in the Toll-like receptor-dependent and -independent antiviral response. Nature 2006;439 (7073):208-11.

[38] Häcker H, Karin M. Regulation and function of IKK and IKK-related kinases. Sci STKE 2006;2006(357):re13.

[39] Tanimura N, Saitoh S, Matsumoto F, Akashi-Takamura S, Miyake K. Roles for LPSdependent interaction and relocation of TLR4 and TRAM in TRIF-signaling. Biochem Biophys Res Commun 2008;368(1):94-9.

[40] Kagan JC, Su T, Horng T, Chow A, Akira S, Medzhitov R. TRAM couples endocytosis of Toll-like receptor 4 to the induction of interferon-beta. Nat Immuno 2008:9(4):361-8.

[41] Rowe DC, McGettrick AF, Latz E, et al. The myristoylation of TRIF-related adaptor molecule is essential for Toll-like receptor 4 signal transduction. Proc Natl Acad Sci USA 2006;103(16):6299-304.

[42] Takeuchi O, Kawai T, Muhlradt PF, et al. Discrimination of bacterial lipoproteins by Toll-like receptor 6. Int Immunol 2001;13(7):933-40.

[43] Takeuchi O, Sato S, Horiuchi T, et al. Cutting edge: role of Toll-like receptor 1 in mediating immune response to microbial lipoproteins. J Immunol 2002;169(1): 10-4 [Baltimore, Md.: 1950].

[44] Buwitt-Beckmann U, Heine $\mathrm{H}$, Wiesmuller K, et al. Toll-like receptor 6-independent signaling by diacylated lipopeptides. Eur J Immunol 2005;35(1):282-9.

[45] Shimizu T, Kida Y, Kuwano K. Triacylated lipoproteins derived from Mycoplasma pneumoniae activate nuclear factor-kappaB through toll-like receptors 1 and 2 . Immunology 2007;121(4):473-83.

[46] Piccinini AM, Midwood KS., DAMPening inflammation by modulating TLR signalling, Mediators Inflamm in press, doi:10.1155/2010/672395 [Electronic publication ahead of print 2010].

[47] Basu S, Binder RJ, Suto R, Anderson KM, Srivastava PK. Necrotic but not apoptotic cell death releases heat shock proteins, which deliver a partial maturation signal to dendritic cells and activate the NF-kappa B pathway. Int Immunol 2000;12 (11):1539-46.

[48] Ohashi K, Burkart V, Flohe S, Kolb H. Cutting edge: heat shock protein 60 is a putative endogenous ligand of the toll-like receptor-4 complex. J Immunol 2000;164(2):558-61.

[49] Wick G, Schett G, Amberger A, Kleindienst R, Xu Q. Is atherosclerosis an immunologically mediated disease? Immunol Today 1995;16(1):27-33.

[50] Wick G, Kleindienst R, Schett G, Amberger A, Xu Q. Role of heat shock protein $65 / 60$ in the pathogenesis of atherosclerosis. Int Arch Allergy Immuno 1995;107(1-3):130-1.

[51] Lee J, Ye J, Gao Z, et al. Reciprocal modulation of Toll-like receptor-4 signaling pathways involving MyD88 and phosphatidylinositol 3-kinase/AKT by saturated and polyunsaturated fatty acids. J Biol Chem 2003;278(39):37041-51.

[52] Miller YI, Viriyakosol S, Binder CJ, Feramisco JR, Kirkland TN, Witztum JL. Minimally modified LDL binds to CD14, induces macrophage spreading via TLR4/MD-2, and inhibits phagocytosis of apoptotic cells. J Biol Chem 2003;278 (3):1561-8.

[53] Bae YS, Lee JH, Choi SH, et al. Macrophages generate reactive oxygen species in response to minimally oxidized low-density lipoprotein: toll-like receptor 4and spleen tyrosine kinase-dependent activation of NADPH oxidase 2. Circ Res 2009;104(2):210-8 [21p following 218].

[54] Stewart CR, Stuart LM, Wilkinson K, et al. CD36 ligands promote sterile inflammation through assembly of a Toll-like receptor 4 and 6 heterodimer. Nat Immunol 2010;11(2):155-61.

[55] Cole JE, Georgiou E, Monaco C. The expression and functions of toll-like receptors in atherosclerosis. Mediators Inflamm 2010:393946.

[56] Edfeldt K, Swedenborg J, Hansson G, Yan Z. Expression of toll-like receptors in human atherosclerotic lesions: a possible pathway for plaque activation. Circulation 2002;105(10):1158-61.

[57] Stemme S, Faber B, Holm J, Wiklund O, Witztum J, Hansson G. T lymphocytes from human atherosclerotic plaques recognize oxidized low density lipoprotein Proc Natl Acad Sci USA 1995;92(9):3893-7. 
[58] Hornung V, Rothenfusser S, Britsch S, et al. Quantitative expression of toll-like receptor 1-10 mRNA in cellular subsets of human peripheral blood mononuclear cells and sensitivity to CPG oligodeoxynucleotides. J Immunol 2002;168(9): 4531-7.

[59] Bourke E, Bosisio D, Golay J, Polentarutti N, Mantovani A. The toll-like receptor repertoire of human $B$ lymphocytes: inducible and selective expression of TLR9 and TLR10 in normal and transformed cells. Blood 2003;102(3):956-63.

[60] Wagner M, Poeck H, Jahrsdoerfer B, et al. IL-12p70-dependent Th1 induction by human B cells requires combined activation with CD40 ligand and CpG DNA. J Immunol 2004;172(2):954-63.

[61] Mansson A, Adner M, Hockerfelt U, Cardell L. A distinct toll-like receptor repertoire in human tonsillar B cells, directly activated by PamCSK, R-837 and CpG2006 stimulation. Immunology 2006;118(4):539-48.

[62] Bernasconi NL, Onai N, Lanzavecchia A. A role for toll-like receptors in acquired immunity: up-regulation of TLR9 by BCR triggering in naive B cells and constitutive expression in memory B cells. Blood 2003;101(11):4500-4.

[63] Genestier L, Taillardet M, Mondiere P, Gheit H, Bella C, Defrance T. TLR agonists selectively promote terminal plasma cell differentiation of B cell subsets specialized in thymus-independent responses. J Immunol 2007;178(12):7779-86.

[64] Gururajan M, Jacob J, Pulendran B. Toll-like receptor expression and responsiveness of distinct murine splenic and mucosal B-cell subsets. PLoS One 2007;2(9): e863.

[65] Krieg AM, Yi AK, Matson S, et al. CpG motifs in bacterial DNA trigger direct B-cell activation. Nature 1995;374(6522):546-9.

[66] Pryshchep O, Ma-Krupa W, Younge B, Goronzy J, Weyand C. Vessel-specific Tolllike receptor profiles in human medium and large arteries. Circulation 2008;118 (12):1276-84.

[67] Yang X, Murthy V, Schultz K, Tatro J, Fitzgerald K, Beasley D. Toll-like receptor 3 signaling evokes a proinflammatory and proliferative phenotype in human vascular smooth muscle cells. Am J Physiol Heart Circ Physiol 2006;291(5): H2334-43.

[68] Yang X, Coriolan D, Schultz K, Golenbock DT, Beasley D. Toll-like receptor 2 mediates persistent chemokine release by Chlamydia pneumoniae-infected vascular smooth muscle cells. Arterioscler Thromb Vasc Biol 2005;25(11):2308-14

[69] Lee J, Lim E, Park D, Lee S, Kim J, Baek S. A combination of Lox-1 and Nox1 regulates TLR9-mediated foam cell formation. Cell Signal 2008;20(12):2266-75.

[70] Funk J, Feingold K, Moser A, Grunfeld C. Lipopolysaccharide stimulation of RAW 264.7 macrophages induces lipid accumulation and foam cell formation. Atherosclerosis 1993;98(1):67-82.

[71] Higashimori M, Tatro JB, Moore KJ, Mendelsohn ME, Galper JB, Beasley D. Role of toll-like receptor 4 in intimal foam cell accumulation in apolipoprotein Edeficient mice. Arterioscler Thromb Vasc Biol 2011;31(1):50-7.

[72] Choi S, Harkewicz R, Lee J, et al. Lipoprotein accumulation in macrophages via toll-like receptor-4-dependent fluid phase uptake. Circ Res 2009;104(12): 1355-63.

[73] Doyle S, O'Connell R, Miranda G, et al. Toll-like receptors induce a phagocytic gene program through p38. J Exp Med 2004;199(1):81-90.

[74] Mullick AE, Soldau K, Kiosses WB, Bell TA, Tobias PS, Curtiss LK. Increased endothelial expression of Toll-like receptor 2 at sites of disturbed blood flow exacerbates early atherogenic events. J Exp Med 2008;205(2):373-83.

[75] Mullick AE, Tobias PS, Curtiss LK. Modulation of atherosclerosis in mice by Tolllike receptor 2. J Clin Invest 2005;115(11):3149-56.

[76] Michelsen KS, Wong MH, Shah PK, et al. Lack of Toll-like receptor 4 or myeloid differentiation factor 88 reduces atherosclerosis and alters plaque phenotype in mice deficient in apolipoprotein E. Proc Natl Acad Sci USA 2004;101(29): 10679-84.

[77] Bjorkbacka $\mathrm{H}$, Kunjathoor VV, Moore KJ, et al Reduced atherosclerosis in MyD88-null mice links elevated serum cholesterol levels to activation of innate immunity signaling pathways. Nat Med 2004;10(4):416-21.

[78] Cole JE, Navin TJ, Cross AJ, et al. Unexpected protective role for Toll-like receptor 3 in the arterial wall. Proc Natl Acad Sci USA 2011;108(6):2372-7.

[79] Bsibsi M, Bajramovic JJ, Vogt MHJ, et al. The microtubule regulator stathmin is an endogenous protein agonist for TLR3. J Immunol 2010;184(12):6929-37 [Baltimore, Md.: 1950].

[80] Guarda G, Braun M, Staehli F, et al. Type I interferon inhibits interleukin-1 production and inflammasome activation. Immunity 2011;34(2):213-23.

[81] Zhang L-N, Velichko S, Vincelette J, et al. Interferon-beta attenuates angiotensin II-accelerated atherosclerosis and vascular remodeling in apolipoprotein E deficient mice. Atherosclerosis 2008;197(1):204-11.

[82] Goossens P, Gijbels MJJ, Zernecke A, et al. Myeloid type I interferon signaling promotes atherosclerosis by stimulating macrophage recruitment to lesions. Cell Metab 2010;12(2):142-53.

[83] Zimmer S, Steinmetz M, Asdonk T, et al. Activation of endothelial Toll-like receptor 3 impairs endothelial function. Circ Res 2011;108(11):1358-66.

[84] Koga N, Suzuki J-ichi, Kosuge H, et al. Blockade of the interaction between PD-1 and PD-L1 accelerates graft arterial disease in cardiac allografts. Arterioscler Thromb Vasc Biol 2004;24(11):2057-62.

[85] Groschel S, Piggott KD, Vaglio A, et al. TLR-mediated induction of negative regulatory ligands on dendritic cells. J Mol Med 2008;86(4):443-55.

[86] Constantinides P. Mast cells and susceptibility to experimental atherosclerosis. Science 1953;117(3045):505-6 [New York, N.Y.]

[87] Caughey GH. Mast cell tryptases and chymases in inflammation and host defense. Immunol Rev 2007;217:141-54.

[88] Bot I, de Jager SCA, Zernecke A, et al. Perivascular mast cells promote atherogenesis and induce plaque destabilization in apolipoprotein E-deficient mice. Circulation 2007;115(19):2516-25.
[89] Kulka M, Alexopoulou L, Flavell RA, Metcalfe DD. Activation of mast cells by double-stranded RNA: evidence for activation through toll-like receptor 3. J Allergy Clin Immun 2004;114(1):174-82.

[90] Jongstra-Bilen J, Haidari M, Zhu S-N, Chen M, Guha D, Cybulsky MI. Low-grade chronic inflammation in regions of the normal mouse arterial intima predisposed to atherosclerosis. J Exp Med 2006;203(9):2073-83.

[91] Yilmaz A, Lochno M, Traeg F, et al. Emergence of dendritic cells in rupture-prone regions of vulnerable carotid plaques. Atherosclerosis 2004;176(1):101-10.

[92] Liu P, Yu Y-RA, Spencer JA, et al. CX3CR1 deficiency impairs dendritic cell accumulation in arterial intima and reduces atherosclerotic burden. Arterioscler Thromb Vasc Biol 2008;28(2):243-50.

[93] Alderman CJJ, Bunyard PR, Chain BM, Foreman JC, Leake DS, Katz DR. Effects of oxidised low density lipoprotein on dendritic cells: a possible immunoregulatory component of the atherogenic micro-environment? Cardiovasc Res 2002;55(4): 806-19.

[94] Nickel T, Schmauss D, Hanssen H, et al. oxLDL uptake by dendritic cells induces upregulation of scavenger-receptors, maturation and differentiation. Atherosclerosis 2009;205(2):442-50.

[95] Jarrossay D, Napolitani G, Colonna M, Sallusto F, Lanzavecchia A. Specialization and complementarity in microbial molecule recognition by human myeloid and plasmacytoid dendritic cells. Eur J Immunol 2001;31(11):3388-93.

[96] Ito T, Amakawa R, Kaisho T, et al. Interferon-alpha and interleukin-12 are induced differentially by Toll-like receptor 7 ligands in human blood dendritic cell subsets. J Exp Med 2002;195(11):1507-12.

[97] Negishi H, Fujita Y, Yanai H, et al. Evidence for licensing of IFN-gamma-induced IFN regulatory factor 1 transcription factor by MyD88 in Toll-like receptordependent gene induction program. Proc Natl Acad Sci USA 2006;103(41): 15136-41.

[98] Schmitz F, Heit A, Guggemoos S, et al. Interferon-regulatory-factor 1 controls Toll-like receptor 9-mediated IFN-beta production in myeloid dendritic cells. Eur J Immunol 2007;37(2):315-27.

[99] Shamshiev AT, Ampenberger F, Ernst B, Rohrer L, Marsland BJ, Kopf M. Dyslipidemia inhibits Toll-like receptor-induced activation of CD8alpha-negative dendritic cells and protective Th1 type immunity. J Exp Med 2007;204(2):441-52.

[100] Weber C, Zernecke A, Libby P. The multifaceted contributions of leukocyte subsets to atherosclerosis: lessons from mouse models. Nat Rev Immunol 2008;8 (10):802-15.

[101] Gordon S, Taylor PR. Monocyte and macrophage heterogeneity. Nat Rev Immunol 2005;5(12):953-64.

[102] Nageh MF, Sandberg ET, Marotti KR, et al. Deficiency of inflammatory cell adhesion molecules protects against atherosclerosis in mice. Arterioscler Thromb Vasc Biol 1997;17(8):1517-20.

[103] Cybulsky MI, Iiyama K, Li H, et al. A major role for VCAM-1, but not ICAM-1, in early atherosclerosis. J Clin Invest 2001;10:1255-62.

[104] Gautier EL, Jakubzick C, Randolph GJ. Regulation of the migration and survival of monocyte subsets by chemokine receptors and its relevance to atherosclerosis. Arterioscler Thromb Vasc Biol 2009;29(10):1412-8.

[105] Swirski FK, Libby P, Aikawa E, et al. Ly-6Chi monocytes dominate hypercholesterolemia-associated monocytosis and give rise to macrophages in atheromata. J Clin Invest 2007;117(1):195-205.

[106] Auffray C, Fogg D, Garfa M, et al. Monitoring of Blood Vessels and Tissues by a Population of Monocytes with Patrolling Behavior. Science 2007;317(5838): 666-70.

[107] Jakubzick C, Tacke F, Ginhoux F, et al. Blood monocyte subsets differentially give rise to $\mathrm{CD} 103^{+}$and $\mathrm{CD} 103^{-}$pulmonary dendritic cell populations. J Immunol 2008;180(5):3019-27 [Baltimore, Md.: 1950].

[108] Landsman L, Bar-On L, Zernecke A, et al. CX3CR1 is required for monocyte homeostasis and atherogenesis by promoting cell survival. Blood 2009;113(4): 963-72.

[109] Cheng C, Tempel D, van Haperen R, et al. Shear stress-induced changes in atherosclerotic plaque composition are modulated by chemokines. J Clin Invest 2007;117(3):616-26

[110] Combadiere C, Potteaux S, Gao J-L, et al. Decreased atherosclerotic lesion formation in CX3CR1/apolipoprotein E double knockout mice. Circulation 2003;107 (7):1009-16

[111] Combadiere C, Potteaux S, Rodero M, et al. Combined inhibition of CCL2, CX3CR1, and CCR5 abrogates Ly6C(hi) and Ly6C(lo) monocytosis and almost abolishes atherosclerosis in hypercholesterolemic mice. Circulation 2008;117(13): 1649-57.

[112] Wu H, Gower RM, Wang H, et al. Functional role of CD11c+ monocytes in atherogenesis associated with hypercholesterolemia. Circulation 2009;119(20): 2708-17.

[113] Mosig S, Rennert K, Krause S, et al. Different functions of monocyte subsets in familial hypercholesterolemia: potential function of CD14+CD16+ monocytes in detoxification of oxidized LDL. FASEB J 2009;23(3):866-74.

[114] Swirski FK, Weissleder R, Pittet MJ. Heterogeneous in vivo behavior of monocyte subsets in atherosclerosis. Arterioscler Thromb Vasc Biol 2009;29(10): 1424-32.

[115] Geissmann F, Jung S, Littman DR. Blood monocytes consist of two principal subsets with distinct migratory properties. Immunity 2003;19(1):71-82.

[116] Sunderkötter C, Nikolic T, Dillon MJ, et al. Subpopulations of mouse blood monocytes differ in maturation stage and inflammatory response. J Immunol 2004;172(7):4410-7 [Baltimore, Md.: 1950]

[117] Nahrendorf M, Swirski FK, Aikawa E, et al. The healing myocardium sequentially mobilizes two monocyte subsets with divergent and complementary functions. J Exp Med 2007;204(12):3037-47. 
[118] Tacke F, Alvarez D, Kaplan TJ, et al. Monocyte subsets differentially employ CCR2, CCR5, and CX3CR1 to accumulate within atherosclerotic plaques. J Clin Invest 2007;117(1):185-94.

[119] Tsou C-L, Peters W, Si Y, et al. Critical roles for CCR2 and MCP-3 in monocyte mobilization from bone marrow and recruitment to inflammatory sites. J Clin Invest 2007;117(4):902-9.

[120] Schlitt A, Heine GH, Blankenberg S, et al. CD14+CD16+ monocytes in coronary artery disease and their relationship to serum TNF-alpha levels. Thromb Haemost 2004;92(2):419-24.

[121] Imanishi T, Ikejima $H$, Tsujioka $H$, et al. Association of monocyte subset counts with coronary fibrous cap thickness in patients with unstable angina pectoris. Atherosclerosis 2010;212(2):628-35.

[122] Ingersoll MA, Spanbroek R, Lottaz C, et al. Comparison of gene expression profiles between human and mouse monocyte subsets. Blood 2010;115(3):10-9.

[123] Geissmann F, Auffray C, Palframan R, et al. Blood monocytes: distinct subsets, how they relate to dendritic cells, and their possible roles in the regulation of T-cell responses. Immunol Cell Biol 2008;86(5):398-408.

[124] Martinez FO, Gordon S, Locati M, Mantovani A. Transcriptional profiling of the human monocyte-to-macrophage differentiation and polarization: new molecules and patterns of gene expression. J Immunol 2006;177(10):7303-11.

[125] Geissmann F, Manz MG, Jung S, Sieweke MH, Merad M, Ley K. Development of monocytes, macrophages, and dendritic cells. Science 2010;327(5966):656-61 [New York, N.Y.].

[126] Bowdish DME, Loffredo MS, Mukhopadhyay S, Mantovani A, Gordon S. Macrophage receptors implicated in the "adaptive" form of innate immunity. Microbes Infect/Institut Pasteur 2007;9(14-15):1680-7.

[127] Gordon S, Martinez FO. Alternative activation of macrophages: mechanism and functions. Immunity 2010;32(5):593-604.

[128] Smith JD, Trogan E, Ginsberg M, Grigaux C, Tian J, Miyata M. Decreased atherosclerosis in mice deficient in both macrophage colony-stimulating factor (op) and apolipoprotein E. Proc Natl Acad Sci USA 1995;92(18):8264-8.

[129] Biswas SK, Mantovani A. Macrophage plasticity and interaction with lymphocyte subsets: cancer as a paradigm. Nat Immunol 2010;11(10):889-96.

[130] Mosser DM, Edwards JP. Exploring the full spectrum of macrophage activation. Nat Rev Immunol 2008;8(12):958-69.

[131] Mantovani A, Sica A, Sozzani S, Allavena P, Vecchi A, Locati M. The chemokine system in diverse forms of macrophage activation and polarization. Trends Immunol 2004;25(12):677-86.

[132] Buono C, Binder CJ, Stavrakis G, Witztum JL, Glimcher LH, Lichtman AH. T-bet deficiency reduces atherosclerosis and alters plaque antigen-specific immune responses. Proc Natl Acad Sci USA 2005;102(5):1596-601.

[133] Shirey KA, Cole LE, Keegan AD, Vogel SN. Francisella tularensis live vaccine strain induces macrophage alternative activation as a survival mechanism. J Immunol 2008;181(6):4159-67 [Baltimore, Md.: 1950].

[134] Li Q, Verma IM. NF-kappaB regulation in the immune system. Nat Rev Immunol 2002;2(10):725-34.

[135] Porta C, Rimoldi M, Raes G, et al. Tolerance and M2 (alternative) macrophage polarization are related processes orchestrated by $\mathrm{p} 50$ nuclear factor kappaB. Proc Natl Acad Sci USA 2009;106(35):14978-83.

[136] Khallou-Laschet J, Varthaman A, Fornasa G, et al. Macrophage plasticity in experimental atherosclerosis. PLoS One 2010;5(1):e8852.

[137] Tiemessen MM, Jagger AL, Evans HG, van Herwijnen MJC, John S, Taams LS. $\mathrm{CD}^{+}{ }^{+} \mathrm{CD} 25^{+} \mathrm{Foxp}^{+}{ }^{+}$regulatory $\mathrm{T}$ cells induce alternative activation of human monocytes/macrophages. Proc Natl Acad Sci USA 2007;104(49):19446-51.

[138] Savage NDL, de Boer T, Walburg KV, et al. Human anti-inflammatory macrophages induce Foxp $3^{+} \mathrm{GITR}^{+} \mathrm{CD}_{2} 5^{+}$regulatory T cells, which suppress via membranebound TGFbeta-1. J Immunol 2008;181(3):2220-6 [Baltimore, Md.: 1950].

[139] Mosser DM. The many faces of macrophage activation. J Leukoc Biol 2003;73(2): 209-12.

[140] Pollard JW. Trophic macrophages in development and disease. Nat Rev Immunol 2009;9(4):259-70.

[141] Lumeng CN, Bodzin JL, Saltiel AR. Obesity induces a phenotypic switch in adipose tissue macrophage polarization. J Clin Invest 2007;117(1):175-84.

[142] Kadl A, Meher AK, Sharma PR, et al. Identification of a novel macrophage phenotype that develops in response to atherogenic phospholipids via Nrf2. Circ Res 2010;107:737-46.
[143] Greaves DR, Gordon S. The macrophage scavenger receptor at 30 years of age: current knowledge and future challenges. J Lipid Res 2009;50:S282-6 [Suppl].

[144] Zeibig S, Li Z, Wagner S, et al. Effect of the oxLDL binding protein Fc-CD68 on plaque extension and vulnerability in atherosclerosis. Circ Res 2011;108(6): 695-703.

[145] Thomas AC, Sala-Newby GB, Ismail Y, Johnson JL, Pasterkamp G, Newby AC. Genomics of foam cells and nonfoamy macrophages from rabbits identifies arginase-I as a differential regulator of nitric oxide production. Arterioscler Thromb Vasc Biol 2007;27(3):571-7.

[146] Johnson JL, Sala-Newby GB, Ismail Y, Aguilera CM, Newby AC. Low tissue inhibitor of metalloproteinases 3 and high matrix metalloproteinase 14 levels defines a subpopulation of highly invasive foam-cell macrophages. Arterioscler Thromb Vasc Biol 2008;28(9):1647-53.

[147] Johnson JL, Newby AC. Macrophage heterogeneity in atherosclerotic plaques. Curr Opin Lipidol 2009;20(5):370-8.

[148] Mantovani A, Garlanda C, Locati M. Macrophage diversity and polarization in atherosclerosis: a question of balance. Arterioscler Thromb Vasc Biol 2009;29 (10):1419-23.

[149] Martinez FO, Sica A, Mantovani A, Locati M. Macrophage activation and polarization. Front Biosci 2008;13:453-61.

[150] Devaraj S, Jialal I. C-reactive protein polarizes human macrophages to an M1 phenotype and inhibits transformation to the M2 phenotype. Arterioscler Thromb Vasc Biol 2011;31(6):1397-402.

[151] Boyle JJ, Harrington HA, Piper E, et al. Coronary intraplaque hemorrhage evokes a novel atheroprotective macrophage phenotype. Am J Pathol 2009;174(3): 1097-108.

[152] Monaco C, Andreakos E, Kiriakidis S, et al. Canonical pathway of nuclear factor kappa B activation selectively regulates proinflammatory and prothrombotic responses in human atherosclerosis. Proc Natl Acad Sci USA 2004;101(15): 5634-9.

[153] Xie QW, Kashiwabara Y, Nathan C. Role of transcription factor NF-kappa B/Rel in induction of nitric oxide synthase. J Biol Chem 1994;269(7):4705-8.

[154] Yamamoto K, Arakawa T, Ueda N, Yamamoto S. Transcriptional roles of nuclear factor kappa B and nuclear factor-interleukin-6 in the tumor necrosis factor alpha-dependent induction of cyclooxygenase-2 in MC3T3-E1 cells. J Bio Chem 1995;270(52):31315-20.

[155] Richmond A, Nf-kappa B. Chemokine gene transcription and tumour growth. Nat Rev Immunol 2002;2(9):664-74.

[156] Iwahashi M, Yamamura M, Aita T, et al. Expression of toll-like receptor 2 on CD16+ blood monocytes and synovial tissue macrophages in rheumatoid arthritis. Arthritis Rheum 2004;50(5):1457-67.

[157] Li M, Carpio D, Zheng Y, et al. An essential role of the NF-kappa B/Toll-like receptor pathway in induction of inflammatory and tissue-repair gene expression by necrotic cells. J Immunol 2001;166(12):7128-35.

[158] Fong CHY, Bebien M, Didierlaurent A, et al. An antiinflammatory role for IKKbeta through the inhibition of "classical" macrophage activation. J Exp Med 2008;205 (6):1269-76.

[159] El Kasmi KC, Qualls JE, Pesce JT, et al. Toll-like receptor-induced arginase 1 in macrophages thwarts effective immunity against intracellular pathogens. Nat Immunol 2008;9(12):1399-406.

[160] Wang L, Gordon RA, Huynh L, et al. Indirect inhibition of Toll-like receptor and Type I interferon responses by ITAM-coupled receptors and integrins. Immunity 2010;32(4):518-30.

[161] Satoh T, Takeuchi O, Vandenbon A, et al. The Jmjd3-Irf4 axis regulates M2 macrophage polarization and host responses against helminth infection. Nat Immunol 2010;11(10):936-44.

[162] Tamura T, Yanai H, Savitsky D, Taniguchi T. The IRF family transcription factors in immunity and oncogenesis. Annu Rev Immunol 2008;26:535-84.

[163] Xu D, Meyer F, Ehlers E, Blasnitz L, Zhang L. Interferon regulatory factor 4 (IRF-4) targets IRF-5 to regulate Epstein-Barr virus transformation. J Biol Chem 2011;286(20):18261-7.

[164] Negishi H, Ohba Y, Yanai H, et al. Negative regulation of Toll-like-receptor signaling by IRF-4. Proc Natl Acad Sci USA 2005;44:15989-94. 